\title{
Vanadium isotope fractionation during magma differentiation in the Gangdese batholith, southern Tibet
}

\author{
WEIXIN LV ${ }^{1}$, FANG HUANG ${ }^{2}$ AND RUI WANG ${ }^{3}$ \\ ${ }^{1}$ University of Science and Technology of China \\ ${ }^{2}$ CAS Key Laboratory of Crust-Mantle Materials and \\ Environments, School of Earth and Space Sciences, University \\ of Science and Technology of China \\ ${ }^{3}$ State Key Laboratory of Geological Processes and Mineral \\ Resources, and Institute of Earth Sciences, China University of \\ Geosciences \\ Presenting Author: lvwx@mail.ustc.edu.cn
}

Vanadium (V) isotope compositions of igneous rocks have the potential to constrain variations of physico-chemical conditions, especially oxidation states during a number of geological processes, such as the accretion of the silicate Earth, partial melting of the upper mantle, formation of magmatic ore, and magma evolution. However, the mechanism of $\mathrm{V}$ isotope fractionation during magmatic differentiation is still challenging to be constrained, which hinders $\mathrm{V}$ isotopes as a tracer for the above processes. Here, we present $\mathrm{V}$ isotope data (reported as $\delta^{51} \mathrm{~V}=1000 \times\left[\left({ }^{51} \mathrm{~V}^{50} \mathrm{~V}_{\text {sample }}{ }^{51} \mathrm{~V} /{ }^{50} \mathrm{~V}_{\mathrm{AA}}\right)-1\right] \%$ ) for 25 fresh igneous rocks (ranging from gabbroic to granitic compositions) from Gangdese magmatic arc in the Himalaya-Tibetan orogenic belt. These samples have $\mathrm{SiO}_{2}$ contents ranging from $37.9 \mathrm{wt} . \%$ to 68.1 wt.\%, $\mathrm{MgO}$ contents from 1.4 wt.\% to $16.7 \mathrm{wt} . \%$, and $\mathrm{V}$ from $89 \mathrm{ppm}$ to $661 \mathrm{ppm}$. Cretaceous samples with $\mathrm{MgO}>6.5$ wt.\% are mostly hornblendite cumulate with $\delta^{51} \mathrm{~V}$ shifting to slightly higher values from $-0.97 \%$ to $-0.68 \%$. Such fractionation is likely driven by the change of cumulate compositions, such as crystallization of Fe-Ti oxides. Except for one Oligocene sample with the highest $\mathrm{MgO}$ content, the rest of the samples contain $\mathrm{MgO}<6.5 \mathrm{wt} . \%$ and whole rock $\delta^{51} \mathrm{~V}$ range from $-0.83 \%$ to $-0.58 \%$, revealing a substantially heavier average $\mathrm{V}$ isotopic composition $(-0.69 \%$ o $\pm 0.14 \%$ ) than the bulk silicate Earth (BSE; $-0.91 \%$ $\pm 0.09 \%$ ) and mid-ocean ridge basalts (MORB; $-0.84 \% \pm \pm 0.10 \%$ ) $[1,2]$. The results suggest that magma differentiation from the lower crust to upward will leave the rocks with significantly heavier $\mathrm{V}$ isotopic composition.

[1] Wu et al. (2018), EPSL 493, 128-139. [2] Qi et al. (2019), GCA 259, 288-301. 